\title{
O RECONHECIMENTO DE IMUNIDADE TRIBUTÁRIA A COLECTIBLE CARD GAME E O NECESSÁRIO RESGATE DO SENTIDO A PARTIR DA HERMENÊUTICA JURÍDICA CRÍTICA
}

\author{
THE ADMISSION OF TAX IMMUNITY FOR COLECTIBLE CARD GAME AND THE \\ NECESSARY RESCUE OF THE SENSE FROM A CRITICAL LEGAL HERMENEUTIC
}

Vicente de Paulo Augusto de Oliveira Júnior

Doutorando em Direito Constitucional Público e Teoria Política, pela Universidade de Fortaleza (UNIFOR/CE). Mestre, com bolsa PROSUP/CAPES, em Direito Constitucional nas Relações Privadas pela Universidade de Fortaleza (UNIFOR/CE). Professor do curso de graduação em Direito da Faculdade Nordeste (Fanor/DeVry Brasil). Coordenador do Grupo de Estudos e Pesquisas em Direito Administrativo e Tributário (GEPDAT).

E-mail: vicenteaugusto2@gmail.com

\section{Eduardo Rocha Dias}

Doutor em Direito pela Faculdade de Direito da Universidade de Lisboa, em Portugal. Mestre em Ordem Jurídica e Constitucional, pela Universidade Federal do Ceará (UFC). Professor titular do curso de pós-graduação strictu sensu

- mestrado e doutorado - em Direito Constitucional, da UNIFOR. Procurador Federal - categoria especial - da

Advocacia Geral da União.

E-mail: eduardo.dias@agu.gov.br

Recebido em: 08/05/2018

Aprovado em: 09/04/2019

RESUMO: O presente trabalho objetiva discutir a aplicação de uma hermenêutica jurídica crítica como forma de resgate do sentido, diante de julgado do Supremo Tribunal Federal, que estendeu a imunidade tributária ao poder-dever de tributar, prevista no artigo 150, inciso VI, alínea "d" aos colectible card game. Ao fazê-lo, o Supremo Tribunal Federal demonstrou a aplicação de uma hermenêutica realística, mas com inconsistências teóricas. Com metodologia lógico-dedutiva, e análise doutrinária, jurisprudencial e de dispositivos legais, concluir-se-á pela defesa de uma hermenêutica que promova um resgate da interpretação constitucional, proporcionando um alcance do sentido autêntico da norma imunizante ao poder-dever de tributar.

Palavras-Chave: Hermenêutica Jurídica Crítica. Imunidade Tributária. Supremo Tribunal Federal.

\begin{abstract}
The present paper aims to discuss the application of a critical legal hermeneutics as a way of recovering the meaning, when the Federal Supreme Court extended the tax immunity to the power-duty tax, according to article 150, item VI, "d" to collectible card game. In doing so, the Court has demonstrated the application of a realistic hermeneutics, but with theoretical inconsistencies. With logical-deductive methodology, and doctrinal, jurisprudential and legal analysis, it will be concluded by the defense of a hermeneutic that promotes redemption of the constitutional interpretation, providing a reach of the authentic meaning of the norm immunizing the power-duty to tax.
\end{abstract}

Key Words: Critical Legal Hermeneutic. Tax Immunity. Federal Supreme Court of Brazil. 
SUMÁRIO: Introdução. 1 O Supremo Tribunal Federal e o reconhecimento de imunidade tributária a colectible card games: um caso (a)típico?. 2 A dupla personalidade do STF e o (des)virtuamento hermenêutico: entre a "síndrome de Abdula" e o "dilema do juiz Ângelo". 3 A hermenêutica jurídica crítica e o resgate de uma interpretação constitucional autêntica: indagações e refutações contra o "estado de exceção hermenêutico". Conclusão. Referências bibliográficas.

\section{INTRODUÇÃO}

As imunidades tributárias ao poder-dever de tributar consistem em relevante instituto na formação da teoria constitucional tributária brasileira, e formam um dos pilares do denominado Sistema Tributário Nacional. Para tanto, são consideradas temática obrigatória à maioria do ementário de disciplinas de Direito Tributário e seus similares, dos cursos de graduação em Direito no País.

Entretanto, apesar do enfoque retro mencionado, as imunidades tributárias permanecem ausentes no interesse do imaginário dos pesquisadores tributaristas. Talvez por constituir assunto fértil, mas sensivelmente complexo, ou ainda em razão de construções dogmáticas no ensino jurídico tributário, que ainda carece de maiores delimitações teóricas aprofundadas. Nesse contexto, determinadas ações, como, por exemplo, as decisões proferidas em sede do Supremo Tribunal Federal - STF, última instância da jurisdição constitucional brasileira, têm o condão de promover uma série de impactos na sistemática jurídico-tributária, e que, quando analisados com pouca (ou quase nenhuma) cautela, podem vir a gerar danos irreparáveis.

E são aqueles impactos que podem vir a fazer a diferença, trazendo à tona uma série de questionamentos, dentre os quais: qual o papel desempenhado pelas imunidades tributárias ao poder-dever de tributar em um Estado Democrático de Direito? Como podem (devem) ser interpretadas tais imunidades, diante de um (teoricamente) rígido Sistema Tributário Nacional? Qual o limite da atividade jurisdicional quando de sua interpretação e eventual aplicação?

Assim, a partir de uma metodologia crítico-sistemática que abordará decisões jurisprudenciais, dispositivos legais e estudos doutrinários, o presente trabalho almeja responder a esses questionamentos. Entretanto, antes de se adentrar na análise crítica acerca do papel do Poder Judiciário e dos juízes quando da realização da atividade interpretativa das imunidades tributárias ao poder-dever de tributar, e que podem gerar um "estado de exceção hermenêutico", faz-se necessário, a título de contextualização, que se exponham os termos sob os quais aquela atividade interpretativa encontrou-se desvirtuada de seu propósito.

Para tanto, discutir-se-á o reconhecimento da imunidade tributária ao poder-dever de tributar para os livros, presente no artigo 150, inciso VI, alínea "d", da Constituição da República Federativa do Brasil, de 1988, para os denominado colectible card games ${ }^{1}-$ CCG, e se a interpretação aplicada pelo STF ao caso concreto condiz com os objetivos determinados para um Estado Democrático de Direito, ou se, quando muito, não formará um verdadeiro "estado de exceção hermenêutico".

\footnotetext{
${ }^{1}$ A expressão colectible card games não apresenta, no mesmo sentido na qual geralmente é empregada, tradução equivalente para o português, que, quando muito, pode ser traduzida como "jogos de cartas colecionáveis". Entretanto, convencionou-se, em razão da maioria desses jogos apresentarem-se como de raciocínio lógicoestratégico, de denominá-los como "jogos de estratégia", ainda que nem todos possam ser classificados nessa categoria. Para os fins deste trabalho, será utilizado o termo em sua delimitação original, qual seja, a do idioma nativo, a fim de que se evitem exageros ou imprecisões conceituais.
}

Revista de Direito Brasileira | Florianópolis, SC | v. 23 | n. 9 | p. 445-460 |Mai./Ago. 2019 
Inicialmente, explorar-se-á o teor da decisão do Recurso Extraordinário com Agravo ARE de $n^{\circ}$. 941463, interposto pela União contra acórdão do Tribunal Regional Federal da $3^{\mathrm{a}}$ Região - TRF3, em 2016, e que, porventura, afastou atividade tributante dos CCG com fulcro na imunidade tributária aos livros e seus derivados.

Dar-se-á prosseguimento com a exposição do paradigma jusfilosófico da interpretação constitucional no Brasil, e a consequência de suas aplicações práticas, quando analisadas diante de um Estado Democrático de Direito, com respaldo em um texto constitucional (aparentemente) rígido.

Finalmente, concluir-se-á a partir da aplicação das formulações teóricas devidamente elencadas e sua aplicação ao caso concreto da imunidade tributária aos CCG, com a finalidade de ser verificar a autenticidade hermenêutica da decisão a ela aplicada.

\section{O SUPREMO TRIBUNAL FEDERAL E O RECONHECIMENTO DE IMUNIDADE TRIBUTÁRIA A COLECTIBLE CARD GAMES: UM CASO (A)TÍPICO?}

Para construir um instrumento de ação social, que consiste na norma jurídica, a estrutura do pensamento humano utilizou-se da lógica e de sua atuação dinâmica. Com isso, todas as regras jurídicas incidem, e somente incidem depois de realizada a sua hipótese, uma vez que foram criadas conforme o pensamento humano, gerando um efeito disciplinador condicionando à realização de uma hipótese (MIRANDA: 1954; XVI).

Diante desse contexto, conclui-se que o jurídico consiste numa realidade espiritual, e toda a fenomenologia jurídica existe e desencadeia-se no mundo do pensamento, que faz parte do mundo em sua totalidade. Entretanto, conectam-se com os fatos do mundo perceptível, sendo toda prova de direitos uma prova dos fatos que a antecedem (BECKER: 2010; 314).

Nesse raciocínio, pode-se elencar a estrutura lógica da norma jurídica, em que a mesma sistematização é seguida pela norma jurídica tributária, decompondo-a em duas partes: a) a hipótese de incidência (denominada como o fato gerador); e b) a própria norma (denominada como regra, ou também, regra de conduta, preceito) (BECKER: 2010; 315).

Definida sua estrutura lógica, composta da hipótese de incidência e a própria norma, e analisada a norma jurídica em sua estrutura dinâmica, verifica-se que ocorre o seguinte fenômeno, devidamente escalonado e caracterizado:

a) Realização da hipótese de incidência (fato gerador): a hipótese deixa de ser hipótese e concretiza-se, tendo em vista que se realizou pelo acontecimento dos fatos nela previsto.

b) Incidência da norma jurídica sobre a hipótese de incidência (fato gerador) realizada: a incidência da norma jurídica tributária somente ocorre depois de realizada a hipótese de incidência, ou seja, com a concretização de seus efeitos.

c) A juridicização da hipótese de incidência (fato gerador): com a incidência da norma jurídica, o fato gerador concretizado juridiciza-se.

d) A Irradiação dos efeitos jurídicos (eficácia jurídica): ocorrem, com a juridicização, a consequência predeterminada pela norma jurídica, ou seja, pela conduta contida dentro da norma. Forma-se a estrutura lógica da norma jurídica tributária. Os efeitos jurídicos decorrentes da irradiação podem, por sua vez, ser assim explicitados:

d.i) Irradiação da relação jurídica: vincula-se o polo positivo (sujeito ativo) ao polo negativo (sujeito passivo).

d.ii) Irradiação do conteúdo jurídico da relação jurídica: direito à prestação com o correlato deve de prestá-la. 
d.iii) Determinação da prestação jurídica: o fazer ou não fazer, no seu devido tempo e lugar.

d.iv) Determinação do objeto da prestação jurídica: aquilo que deve ser feito ou não deve ser feito. Para se obter a determinação do objeto da prestação jurídica tributária, a própria norma define:

d.iv.i) o elemento dentre os múltiplos que integram a composição da hipótese de incidência, que deverá servir de base de cálculo;

d.iv.ii) o método, que consiste no peso ou medida ou valor para converter a base de cálculo em cifra;

d.iv.iii) a alíquota, que, uma vez calculada sobre a base de cálculo já convertida em cifra, dará como resultado uma segunda cifra, a qual corresponde à grandeza do objeto (tributo) da prestação jurídica tributária.

e) Finalmente, a extinção da irradiação da relação jurídica (d.i) e, também, da irradiação do conteúdo jurídico da relação jurídica, mediante a realização da prestação jurídica.

Porém, deve ser ressaltado que os efeitos jurídicos elencados nos itens "c", "d" e "e" correspondem a consequências prescritas pela norma, que, conjuntamente ao fato gerador, compõem a estrutura lógica da regra jurídica (BECKER: 2010; 316).

Em suma, pode-se verificar que a norma tributária segue a sistemática geral da norma jurídica, em que a conjugação da hipótese de incidência com a sua realização no mundo dos fatos é que formará a obrigação tributária. Pode-se, ainda, ser exemplificada a relação jurídicotributária, com a formação da obrigação de pagar tributos, da seguinte maneira:

$1^{\circ}$ ). Determinado indivíduo adquire a propriedade de um veículo automotor. Ao adquirir a propriedade do veículo, realiza-se a hipótese de incidência (o fato gerador) do Imposto sobre a Propriedade de Veículos Automotores (IPVA).

$2^{\circ}$ ). Prevê o artigo 155, inciso III da CRFB/88 que os Estados-membros e o Distrito Federal têm competência para instituí-lo. Com a concretização do fato gerador, ocorre a incidência da norma jurídica sobre a hipótese de incidência, ou seja, os efeitos jurídicos (o direito de receber e o direito de pagar) ocorrem somente após a incidência concretizada.

$3^{\circ}$ ) A incidência da norma jurídica sobre a hipótese de incidência promove sua juridicização, tornando-se, para tanto, a propriedade sobre o veículo (o que concretizou a hipótese de incidência) relevante juridicamente.

$4^{\mathrm{o}}$ ). Ocorre a irradiação dos efeitos jurídicos, ou seja, as consequências predeterminadas pela regra de conduta (adquirir um veículo automotor) dentro da norma jurídica. Primeiramente, irradia-se a relação jurídica, vinculando o proprietário do veículo com a Administração Pública, representada pelos Estados-membros e o Distrito Federal. Em seguida, irradia-se o conteúdo jurídico da relação jurídica, tendo o proprietário o dever de prestar com sua obrigação.

$5^{\circ}$ ). Determina-se a prestação jurídica, com o dever de fazer ou não fazer do IPVA, com o seu tempo e lugar especificados. Em seguida, determina-se o objeto da prestação jurídica, com a base de cálculo, o método e a alíquota referente ao imposto. Finalmente, extingue-se a relação obrigacional do proprietário com o pagamento do imposto.

Portanto, a norma jurídica tributária contém a determinação dos casos em que se cumpre determinada obrigação (pagar um tributo); as pessoas obrigadas a cumpri-la (sujeitos ativo e passivo); a sua quantia; e os modos e a forma como a obrigação tributária deve ser liquidada e cumprida, sendo matéria regulamentada pelo Estado moderno no ordenamento jurídico com disposições imperativas, e cuja observância vinculam tanto os contribuintes como os órgãos 
estatais (GIANNINI: 1957; 67). E o próprio conceito de tributo para o ordenamento jurídico brasileiro demonstra suas características.

Conforme estabelecido no artigo $3^{\circ}$ da Lei de $n^{\circ}$. 5.172, de 25 de outubro de 1966, também denominado como Código Tributário Nacional (CTN), tributo consiste "em toda prestação pecuniária compulsória, em moeda ou cujo valor nela se possa exprimir, que não constitua sanção de ato ilícito, instituída em lei e cobrada mediante atividade administrativa plenamente vinculada". Ou seja, tributo pode ser considerado um dos recursos oferecidos ao Estado para se obter os meios pecuniários necessários ao desenvolvimento de suas atividades, pertencente, assim, aos fenômenos das finanças públicas e sendo objeto de estudo por parte da ciência ou das ciências que se ocupam delas (JARACH: 1989; 41).

Mas, ao mesmo tempo, não pode o tributo ser afastado dos demais recursos estatais em razão de suas características jurídicas, resultando de uma prestação coativa por parte dos particulares ao Estado e resultado da relação jurídica formada entre os sujeitos ativo e passivo da obrigação, ou seja, uma relação obrigacional de direito público, estritamente vinculada à lei (NOGUEIRA: 1974; 115).

Assim, pode-se afirmar que resta corroborado o entendimento exposto no ordenamento jurídico brasileiro, que defende, no artigo $5^{\circ}$, inciso II, da CRFB/88 que "ninguém será obrigado a fazer ou deixar de fazer alguma coisa senão em virtude de lei". Nesse contexto, a relação jurídico-tributária corresponde aos anseios do direito público, manifestando-se pelo poder de império do Estado (FONROUGE: 1973; 87).

Entretanto, o próprio Estado não poderá atuar discricionariamente, e é condicionado ao respeito às disposições legais - princípio da legalidade, razão pela qual pode ser atribuída à relação jurídico-tributárias as características de uma obrigação ex lege (BUJANDA: 1966; 1922).

Para que exista a formação da obrigação tributária, faz-se necessário, de maneira semelhante à um espelho, que se reflita o retrato da relação de fato, ou seja, o espelho (a lei) pode existir, mas somente refletirá a imagem do fenômeno tributável quando este estiver na sua frente. E, assim, se não houver o espelho, também não haverá o reflexo do fenômeno tributável, inexistindo a formação da obrigação tributária (NOGUEIRA: 1974; 116).

Entretanto, não existe uma norma jurídica para a hipótese de incidência, outra para a própria norma, outra para a base de cálculo, outra para a alíquota, e assim sucessivamente. Todos esses elementos compõem a mesma estrutura lógica de uma única norma jurídica, resultado de diversas leis ou artigos de leis (BECKER: 2010; 319).

Mas a norma jurídica não pode ser confundida com a lei; a norma jurídica é resultante da totalidade do sistema jurídico formado pelas leis. A norma jurídica não é lei, conquanto lei seja norma jurídica, ou seja, o gênero norma jurídica envolve as espécies de lei, além das formas consuetudinária, jurisprudencial e doutrinária (VASCONCELOS: 2006; 50-51).

Dessa forma, verifica-se que a relação jurídica-tributária consiste na formação da obrigação tributária, em razão da complementação da hipótese de incidência com o fato gerador do tributo, vinculando o sujeito ativo (o Poder Público) e o sujeito passivo, seja ele direto (contribuinte) ou indireto (responsável) no cumprimento da obrigação. Mas essa mesma incidência dependerá, em última instância, da previsão normativa e devidamente delimitada de uma competência tributária.

Portanto, o afastamento da incidência tributária somente poderia ocorrer em medidas excepcionais, e privilegiando direitos e garantias fundamentais, dentre as quais inclui-se a imunidade tributária ao poder-dever de tributar, elencada, primordialmente, no artigo 150 da $\mathrm{CRFB} / 88$.

E, por se tratar a competência tributária de uma poder-dever (quase uma faculdade, se não houvessem limites) que os entes políticos detêm de criar, em abstrato, tributos, estes poderão fazê-lo mediante a atenção a uma série de critérios. Devem descrever, legislativamente, suas 
hipóteses de incidência, seus sujeitos ativos, seus sujeitos passivos, suas bases de cálculo e suas alíquotas. Aquela mesma competência detém fronteiras, assim, a partir das diretrizes, diretas (explícitas) ou indiretas (implícitas), traçadas pelo texto constitucional. Nesse contexto, a imunidade tributária ao poder-dever de tributar auxilia a delimitar o campo jurídico de atuação dos tributos, e, ao mesmo tempo, corrobora como forma de restrição (quase um bloqueio) ao exercício da competência. Portanto, enquanto há um poder-dever de se criarem tributos (caráter positivo), há uma série de limites para fazê-lo (caráter negativo).

O campo de incidência da norma jurídica tributária é identificado mediante um processo de qualificação dos fatos, conforme mencionado anteriormente, restando, portanto, facilmente identificáveis as ocasiões em que a não incidência se sucederá. Por outro lado, se a não incidência é decorrente de expressa disposição constitucional (bloqueio ao seu exercício, ou simplesmente incompetência), ocorrerá a imunidade tributária ao poder-dever de tributar (SOBRINHO; 1996: 102). As imunidades tributárias consistem em limitações ao próprio poder impositivo, expressas por intermédio de proibições ou exclusões de competência, com o fito de não apenas impedir a cobrança de tributos, mas também para vedar, em princípio, a competência do legislador ordinário, com textos proibitivos, normativos e autoaplicáveis de hipóteses negativas de atribuição de competência tributária (NOGUEIRA: 1992; 22-23).

Imunidades atuam no âmbito da definição e concessão da competência tributária pelo texto constitucional, e não representam, sequer, isenções (atua no exercício da competência tributária, sendo considerada, em muito, como abandono ou indiferença a determinada receita), ou de não incidência (a incidência ocorrerá, mas não há competência - poder-dever - para realizar a instituição, cobrança ou execução de determinada exação tributária).

Apesar de alguns doutrinadores, definirem as imunidades tributárias como "hipóteses de não-incidência tributária constitucionalmente qualificadas" (BALEEIRO; 2007: 241), verifica-se que o exercício da competência consiste em um poder-dever, devidamente estabelecido constitucionalmente, por um poder constituinte originário, mas que geram às pessoas às quais se endereçam uma garantia de não ser alvo de exações tributárias. São, portanto, bloqueios constitucionais ao exercício da competência, ou, tão-somente, atos de incompetência tributária, cujo poder-dever fora removido pelo próprio texto constitucional.

Deve-se ressaltar que imunidades protegem e interessam a pessoas, e não a objetos, por constituírem garantia ao contribuinte, e formam, portanto, cláusula pétrea, modificável apenas por um novo movimento de poder constituinte originário, ainda que a doutrina, insistentemente, tenta classificar as imunidades como objetivas (quando existem em razão de objetos ou fatos juridicamente relevantes), subjetivas (em razão da qualidade ou natureza de determinada pessoa ou grupos de pessoas) e mistas (quando concedidas mediante ambas as apreciações).

Por si só, tais normas são de eficácia plena e aplicabilidade imediata, produzindo os seus efeitos independentemente da edição de normas inferiores, como leis, decretos, portarias, atos administrativos, entre outros, que possam explicitá-las. Seu conteúdo é ou deve ser concretizado no plano constitucional, e, em última análise, por intermédio de uma interpretação criadora. A imunidade, no caso, assemelha-se ao primeiro âmbito (ANDRADE: 1998; 140). Assim, faz-se mister ressaltar que desobedecer a uma norma imunizante equivale a incidir em inconstitucionalidade, ou, de forma mais abrangente, significa que as imunidades "tornam inconstitucionais as leis ordinárias que as desafiam" (BALEEIRO: 2007; 87).

Mesmo que se tenha delineado a importância das imunidades, e sua devida caracterização para o Direito Tributário, essa medida não impede que se pratiquem excessos em sua aplicação, quando, não muito, ocorrem aplicações por demais restritivas, fora de sua real potencialidade de aplicação. Em parte, isso se deve ao fato de que as imunidades tributárias, em razão de sua complexidade e, ao mesmo tempo, sensibilidade, em razão da carga valorativa envolvida, ainda não são estudadas com maior propriedade pela doutrina brasileira. Alguns 
autores, inclusive, evitam a temática, e simplesmente aceitam reproduzir seus conceitos, em um sistema dogmático de sentido. E isso se reflete, por vezes, na jurisprudência.

Para ilustrar tal cenário, pode-se utilizar como referencial uma decisão proveniente da análise, pelo STF, do Recurso Extraordinário com Agravo (REA), de nº 941.463, em 07 (sete) de março de 2016. O recurso, que fora interposto pela União contra acórdão do Tribunal Regional Federal da $3^{\text {a }}$ Região (TRF3), tinha como objetivo afastar o reconhecimento de imunidade tributária ao poder-dever de tributar dos denominados colectible card games e seus similares, os quais, conforme alegação da referida Corte, assemelhavam-se a livros e demais obras de caráter literário, e, portanto, alcançariam a mesma imunidade concedida a estes pela CRFB/88.

Conforme disposição do artigo 150, inciso VI, alínea “d”, é vedado à União, aos Estados, ao Distrito Federal e aos Municípios, sem prejuízo de outras garantias asseguradas ao contribuinte, instituir impostos sobre "livros, jornais, periódicos e o papel destinado à sua impressão". Apesar do texto constitucional expressamente referir-se aos termos "livros", "jornais", "periódicos" e "o papel destinado à sua impressão", reconheceu o TRF3 que referida imunidade era objetiva (portanto, concedida em razão de fatos ou objetos com elevada relevância jurídica), e que fora incluída na $\mathrm{CRFB} / 88$ com o fito de resguardar valores, quais sejam, o da liberdade de pensamento e de comunicação, bem como a cultura, a informação e a educação.

Ainda conforme o acórdão, por mais que a imunidade tributária ao poder-dever de tributar consista em exceção à regra jurídica de tributação (o que, teoricamente, é estranho, tendo em vista que o ente político não detém competência e, portanto, não seria nada estranho, mas, simplesmente, legítimo), não seria razoável atribuir-lhe interpretação limitada, de forma a incluir os CCG em classificação tributária que fosse diferente da dos livros e seus assemelhados. Finalmente, assentou o acórdão que o vocábulo "livro", contido no dispositivo constitucional, "não se restringe à convencional coleção de folhas de papel, cortadas, dobradas e unidas em cadernos, mas sim em qualquer suporte (disco, disquete, cartões, vídeos e outros), nos quais seja possível antever a divulgação de material literário".

Nesse contexto, quando da análise do acórdão pelo STF, restou afastada a eventual incidência de Imposto de Importação (II) sobre os CCG, uma vez que, conforme voto proferido pelo Ministro Dias Toffoli, o acórdão emitido pelo TRF3 concluiu que os bens importados se enquadrariam na classificação tarifária que atribui a imunidade tributária prevista no artigo 150 , inciso VI, alínea "d" da CRFB/88.

O objetivo da União, quando impetrou o recurso, seria o de redefinir a classificação tributária dos CCG, retirando-lhes daquela de livros e assemelhados, mas, para tanto, seria necessário o reexame de fatos e provas, o que é expressamente vedado em sede de recurso extraordinário, conforme a súmula 279 do próprio Supremo. E complementou o ministro afirmando que restou verificado que o cerne da controvérsia estaria na real classificação dos bens importados. Porém, para ultrapassar o entendimento do Tribunal de origem e acolher a pretensão da agravante, "seria necessário o revolvimento do conjunto fático probatório constante nos autos, o que é vedado em sede de apelo extremo". Em seguida, foi concedida a negativa ao seguimento do recurso.

Resta evidenciado que a interpretação utilizada pelos magistrados, tanto em sede de TRF3, como no STF, apresenta certas inconsistências. Inicialmente, da decisão retro mencionada podem-se elencar as seguintes colocações, tanto especificamente do acórdão emitido pelo TRF3, bem como do julgamento do recurso extraordinário denegado pelo STF:

a) A imunidade tributária ao poder-dever de tributar concedida a livros, jornais, periódicos e ao papel destinado à sua impressão é objetiva, e que fora incluída no texto constitucional com o objetivo de resguardar uma série de valores, dentre os quais encontram-se a liberdade de expressão e cultura.

b) Em razão da finalidade à qual foi criada, a imunidade não poderia limita-se aos vocábulos elencados, quais sejam "livros", "jornais", "periódicos" e ao "papel 
destinado à sua impressão", podendo, portanto, englobar outros termos assemelhados, como, no caso concreto, os colectible card games.

c) Que o próprio vocábulo "livro" é extensivo a outras formas de apresentação, diferentes daquelas que podem, convencionalmente, serem definidas para livros, tal como a de papéis cortados, organizados e colados no formato de um livro. Portanto, os colectible card games, nas mais variadas formas que podem ser oferecidos, alcançariam, conceitualmente, a mesma finalidade do "livro", e, consequentemente, está protegido pela mesma imunidade destes.

d) O STF, em sede de recurso extraordinário, não poderia acolher o pedido efetuado pela União, em razão de que seriam necessárias novas averiguações fático-probatórias, o que é vedado nesse instrumento processual.

Diante dos argumentos expostos, é possível verificar-se que são feitas uma série de ressalvas e exceções para a imunidade e, ainda, uma interpretação por demais extensiva (elástica, por assim dizer) para os termos elencados no texto constitucional. Essas medidas, por si só, já seriam suficientes para a demonstração de um caso atípico de julgamentos na seara tributária, se fossem, de fato, novidade. Entretanto, a busca por exceções e, quando cabíveis, exceções das exceções, já foi evidenciada em outros julgados do próprio STF.

Pode-se citar, mais uma vez, a título de complementação, a mesma imunidade elencada, qual seja, a dos livros e seus assemelhados, e de como o posicionamento do STF gerou ainda mais inconsistências, como no Recurso Extraordinário (RE) de no. 221.239, de 2004, que reconheceu o álbum de figurinhas como semelhante a um livro ou outra obra literária de conteúdo cultural relevante, e do Recurso Extraordinário de $\mathrm{n}^{\circ}$. 330.817, de 2012, que previa a extensão da imunidade de livros e assemelhados a outros formatos, como o de livro eletrônico ou e-books.

No primeiro caso, o do RE de $\mathrm{n}^{\mathrm{o}}$. 221.239, o STF conheceu recurso interposto pela Editora Globo S/A, contra decisão proferida pelo Tribunal de Justiça do Estado de São Paulo (TJ/SP). Referido tribunal entendera que o álbum de figurinhas da telenovela da Rede Globo, "Que Rei Sou Eu", não poderia servir como mecanismo de divulgação cultural ou educativa e que, portanto, como mero veículo de propaganda, não teria direito à imunidade prevista pelo artigo 150, inciso VI, alínea "d" da CRFB/88, que a associa ao vocábulo "livro".

A Editora Globo afirmou, em sede do recurso, que os álbuns de figurinhas, verdadeiros livros ilustrados, com cromos adesivos de complementação, são elementos de didática moderna, e necessários à educação infantil, merecendo, portanto, serem contemplados como a referida imunidade constitucional concedida aos livros, jornais e periódicos, cujo objetivo seria o de garantir a liberdade de pensamento e o direito de crítica.

Quando do julgamento, o STF entendeu por dar provimento ao recurso, e, assim, reverteu a decisão originalmente proferida pelo TJ/SP, e estendendo a imunidade tributária aos álbuns de figurinhas. No julgamento, a ministra relatora Ellen Gracie afirmou que o texto constitucional, em momento algum, faz menção ao valor cultural ou artístico da medida. E ainda, que "[...] não há no texto da Lei Maior restrições em relação à forma de apresentação de uma publicação. [...] o fato de figuras, fotos ou gravuras de uma determinada publicação serem vendidas separadamente em envelopes lacrados não descaracteriza a benesse [...]".

Por sua vez, no RE de no .330 .817 , o Estado do Rio de Janeiro contestou decisão da $11^{\mathrm{a}}$ Câmara Cível do Tribunal de Justiça do Estado do Rio de Janeiro (TJ/RJ), que, julgando mandado de segurança impetrado por uma editora, reconheceu a imunidade relativa ao Imposto sobre a Circulação de Mercadorias e Serviços (ICMS) na comercialização de uma enciclopédia jurídica eletrônica. Segundo assentado no acórdão, "livros, jornais e periódicos são todos os impressos ou gravados, por quaisquer processos tecnológicos", e ainda, "que transmitem aquelas ideias, informações, comentários, narrações reais ou fictícias sobre todos os interesses humanos, por meio de caracteres alfabéticos ou por imagens e, ainda, por signos". 
O Estado do Rio de Janeiro sustentou que os livros eletrônicos consistem em forma diferenciada de divulgação da obra, e que a imunidade prevista somente protegeria o livro, jornal e periódico impressos, ou o papel destinado à sua impressão. Entretanto, reconheceu o STF, ao analisar a repercussão geral da matéria, segundo o Ministro Dias Toffoli, que "sempre que se discute a aplicação de um benefício imunizante para determinados bens, sobressai a existência da repercussão geral da matéria, sob todo e qualquer enfoque", tendo em vista que "a transcendência dos interesses que cercam o debate são visíveis tanto do ponto de vista jurídico quanto do econômico".

O ministro complementou seu voto afirmando, ainda, que a doutrina e jurisprudência já haviam formado extenso debate acerca da temática, com a formação de correntes restritivas e extensivas. Para a corrente restritiva, de forte viés liberal (conforme o voto, ressalte-se), a imunidade alcançaria apenas aquilo que se pudesse compreender dentro da expressão "papel destinado à sua impressão". Por outro lado, a corrente extensiva defende que a imunidade poderia adequar-se a novos métodos e meios de publicação, e, portanto, seria extensível aos livros eletrônicos. Essa corrente foi aquela adotada pelo STF.

Se depreende, da análise de referidos julgados, que, diante de critérios de atribuição de sentido, e métodos (ou quase-métodos e, talvez, falsos-métodos) distintos, o mesmo tribunal, qual seja, o STF, atuou de forma dispare, e, mesmo diante de casos aproximados, apresentou, em seus julgados, inconsistências. De um lado, atuou de forma restritiva e com aplicação da própria letra da lei, sem ressalvas (no caso dos colectible card games), ou, por outro lado, o próprio STF agiu com aplicação elástica e extensiva da lei, utilizando, como parâmetro, metodologias, correntes jurídico-doutrinárias-dogmáticas que, por sua vez, fogem das características essenciais da imunidade tributária (no caso do álbum de figurinhas e dos e-books).

Para que se possa realizar uma análise aprofundada da interpretação utilizada pelo Supremo, e suas implicações, faz-se necessário que se exponha o dilema percorrido pela hermenêutica jurídica no Brasil, com seus devaneios realísticos e/ou filosóficos, bem como se possa elencar soluções para os casos concretos. E é o que se proporá a seguir.

\section{A DUPLA PERSONALIDADE DO STF E $O$ (DES)VIRTUAMENTO HERMENÊUTICO: ENTRE A "SÍNDROME DE ABDULA" E O "DILEMA DO JUIZ ÂNGELO"}

A concretização da Pós-modernidade trouxe consigo uma série de modificações, tanto nas relações sociais, como no cenário de construção do Estado e, consequentemente, dos ordenamentos jurídicos. Sai de cena, portanto, o modelo de Estado Social (denominado ainda de Estado-providência ou Welfare State), e encontra-se o ordenamento jurídico brasileiro, a partir da promulgação da CRFB/88, de um Estado Democrático de Direito.

A modernidade, nesse ínterim, tinha como elemento fundamental uma dupla possibilidade para a humanidade. Primeiramente, considerava a realização da razão para o desenvolvimento universal de um sistema social que, por suas características, concretizasse um valor de "igualdade formal", por intermédio de uma gradativa redução das desigualdades no mundo (GENRO: 1996; 76). Em segundo lugar, deve-se ressaltar que essa redução não ocorreu. Muito pelo contrário, no Brasil, particularmente, o que ocorreu foi um aprofundamento da irracionalidade, com o aumento das desigualdades sociais e a consolidação de relações cada vez mais alienadas (SANTOS: 1999; 34).

Assim, pode-se afirmar que as modificações retro mencionadas são responsáveis, em grande parte, pelas tendências transformadoras, desconstrutoras ou reconstrutoras de alguns pressupostos que, teoricamente, se adaptavam à construção de um Estado Moderno (MARQUES NETO: 2002; 29-33). Mas deve-se alertar que essas alterações também impactaram o cenário 
científico-jurídico. Para tanto, o paradigma moderno da neutralidade científica, em muito caracterizado por diversas formas de positivismo, é questionado pela pós-modernidade, uma vez que, ao mesmo tempo em que a modernidade representou a emancipação de uma ciência por demais obscurecida pelos dogmas medievais, cujo auge epistemológico fora vivenciado pelas próprias ideias positivistas lógicas (e suas variações), ainda assim, esta foi condição para uma "ciência sem consciência" (WARAT: 1995; 14-15).

Por sua vez, faz-se mister destacar que, mesmo com a promulgação de uma Constituição de cunho eminentemente democrático, os legados da modernidade longe estão de serem realizados no Brasil, ainda que o texto constitucional possa ser considerado como condição de possibilidade para a transformação social, e não como obstáculo a essas mudanças. O modelo estatal de Estado Social ou Estado-providência não passa de um mero simulacro em solo brasileiro (STRECK: 2014; 333).

Verifica-se uma espécie de dívida social a ser resgatada. De um lado, um texto constitucional dirigente, com objetivos e fundamentais republicados de caráter eminentemente democráticos, que elevaram o número de direitos e garantias a um número jamais antes verificado no Brasil. Entretanto, apresentando uma estrutura político-jurídica de características liberal-individualista, o Direito é instrumentalizado como um campo privilegiado de concretização de direitos sociais, muitos dos quais ainda constituem legado de um Estado Social que, na prática, não ocorreu.

A mudança assemelha-se, em muito, a um ramalhete de flores. Enquanto que a $\mathrm{CRFB} / 88$, por prever o respeito e a concretização de direitos e garantias fundamentais, bem como de direitos sociais como um todo, o Brasil ainda carecia de condições propícias para esse incremento jurídico, recebimento, em muito, diante de um modelo liberal-individualista que desconhecia essa medida. Tal como um ramalhete repleto de flores, o Estado brasileiro consiste em um estrito vaso, e não permitirá, nesse momento, que todas as flores ali sejam apostas. $\mathrm{O}$ resultado não poderia ser outro: flores cairão na mesa e, eventualmente, morrerão, salvo se o vaso for trocado ou aumentar suas dimensões.

Para a concretização efetiva dos direitos sociais e dos direitos e garantias fundamentais previstos, fez-se necessário o deslocamento, do Poder Legislativo e do Poder Executivo, dessa função realizadora, e passa-se ao Judiciário o papel de defensor último dessas conquistas. A problemática, entretanto, está no fato de que a dogmática jurídica tem obstaculizado a efetivação/realização daqueles direitos (WARAT: 1995; 18-20).

E o obstáculo pode ser representado por dois elementos essenciais, e indissociáveis: a) com o limite das reflexões jurídicas enquanto paradigmas de modelo ou modo de produção liberal-individualista do Direito e, b) pela permanência, no plano do imaginário gnosiológico dos juristas de diversas posturas assentadas na filosofia da consciência, bem como no realismo filosófico, ainda com forte presença no Brasil (STRECK: 2014; 334).

Portanto, como superar tal obstáculo? Como, na prática, poderá o Direito, interpretado e aplicado, indagar, descobrir, criar? Qual o papel da dogmática jurídica nesse movimento efetivador/realizador, e quais os seus impactos nos diversos ramos do Direito?

Para responder a esses questionamentos, bem como compreender o papel da dogmática jurídica na apreciação e aplicação do Direito, deve-se ressaltar que a crise de paradigmas instaurada no Brasil, em plena pós-modernidade, em muito sustenta uma verdadeira disfuncionalidade da ordem jurídica.

A disfuncionalidade é decorrente de um modo de produção eminentemente liberalindividualista, em confronto com um campo jurídico (ordenamento jurídico com uma Constituição que apresenta amplo rol de direitos e garantias fundamentais, fundamentos e valores democráticos e, corpo - teoricamente - rígido de disposições) propício para uma posição de conhecimento, contemplação e assunção do operador (aplicador) do Direito enquanto ser criativo (criador), mesmo que utilize, para tanto, da mesma dogmática jurídica (STRECK:2014; 334). 
O intérprete, por consequência, acostumado a um modo de produção de cunho liberalindividualista, depara-se com uma condição pouco favorável e, por vezes, estranha ao que, habitualmente, aplicava, tendo em vista que o texto constitucional vigente ampliou o rol de direitos e suas garantias. E, nessa condição, convive o intérprete, muitas vezes, com uma constante transição entre a "síndrome de Abdula" e o "estado de exceção hermenêutico consubstanciado no "dilema do juiz Ângelo".

Na obra Se una notte d'inverno un viaggiatore, de Italo Calvino, está presente uma breve parábola acerca de Maomé e Abdula, e que pode auxiliar na compreensão da primeira feição do intérprete do Direito no Brasil.

Segundo a estória, Alá ditava o Corão para Maomé que, por sua vez, o repassava para Abdula, o escrivão. O papel de Abdula era considerado necessário para Alá, uma vez que as disposições do Corão estariam dispostas em sentenças escritas. Maomé sabia disso, e permitiu ao escrivão que dispusesse da conclusão de algumas sentenças. Mas Abdula, ao perceber o feito, e por não ter consciência do seu papel e do seu poder - afinal, estava transcrevendo disposições divinas que regulariam os demais - perdeu a fé em Alá, tendo em vista que, ao mesmo tempo, perdeu a fé no que escrevia e em si mesmo enquanto escrivão (CALVINO: 1980; 213).

A parábola evidencia uma "síndrome de Abdula", aplicável aos intérpretes e demais "operadores do Direito", e trata-se de uma patologia que acomete a dogmática jurídica, especialmente na doutrina. Especialmente no Brasil, há uma inautêntica tradição, e que persiste na pós-modernidade, no sentido de retratar os conceitos, definições e soluções dos problemas jurídicos a partir daquilo que foi dito anteriormente pelo portador, autorizado, da fala. Portanto, os intérpretes e aplicadores não conhecem (ou ignoram) as suas possibilidades hermenêuticas de produção do sentido, e, em grande parte, apenas atuam como reprodutores dos elementos jusdogmáticos, colocados pelo campo jurídico. Em suma, perderam a fé em si mesmos enquanto intérpretes, e apenas aguardam que o processo hermenêutico lhes aponte a correta (ou ao menos a mais aproximada) interpretação da lei (STRECK: 2014; 334-335).

Entretanto, em determinados momentos, em confronto com um campo jurídico de amplo respeito (ao menos em teoria) de direitos sociais e com repleto garantismo, o intérprete e aplicadores do Direito podem se inserir no "dilema do juiz Ângelo", retratado a partir da comédia Measure for Measure, de William Shakespeare.

Retrata a estória a ascensão e descenso de Ângelo. Enquanto se ausenta de Viena, alegando que irá à Polônia, o duque Vicêncio relega o comando da cidade a Ângelo, deixando-o com plena autoridade e com Éscalo, seu auxiliar, uma vez que não queria de desgastar politicamente em face dos desmandos que ocorriam na cidade, dominada pela corriqueira luxúria em todas as camadas sociais, ainda que existissem leis que punissem a fornicação e a luxúria com graves penas. Essas leis, porém, em pouco aplicadas havia mais de 14 (catorze) anos, e muitos cidadãos a negligenciaram ou sequer tomaram conhecimento delas.

Por esses motivos, o duque, que permanecera na cidade disfarçado de padre, deixara Ângelo no comando da cidade, tendo em vista que era considerado como um homem de conduta correta, mas fria, e com profundo conhecimento das leis e das ciências de Estado. Portanto, Ângelo não hesitaria em realizar o que, em teoria, seria o mais adequado ao cumprimento das leis da cidade. Ao assumir o poder, Ângelo toma como uma de suas primeiras medidas a condenação de Cláudio, ao constatar que este havia mantido relações sexuais com sua namorada, Julieta, sobrevindo uma gravidez. Preso, Cláudio encontra-se com Lúcio, a quem pede que encontre sua irmã Isabella, que recentemente entrara para um convento.

Conhecida por sua virtude moral e intelectual, Isabella vai ao encontro de Ângelo, pedindo o seu perdão, e que poupasse a vida de Cláudio. Primeiramente, Ângelo nega o pedido de Isabella, alegando que nada poderia fazer, tendo em vista que a punição estava tipificada em lei, e que a letra da lei deveria ser cumprida à risca, mas, encantado com sua beleza, propõe que a futura freira troque sua castidade pela vida de seu irmão. 
Inicialmente, Isabella recusa a oferta de Ângelo, mas é convencida por Vicêncio, então padre disfarçado, a enganar o governante substituto para desmascará-lo. Isabella, então, marca um encontro com Ângelo, mas, em seu lugar, envia Mariana, sua prometida esposa, mas que não teve o casamento concretizado por ter perdido o dote prometido. Mariana, prontamente, aceita a falcatrua, e, após marcado o encontro, desposa-se com Ângelo.

Acreditando que havia mantido encontro carnal com Isabella, irmã do condenado, o governante substituto não modifica a sua sentença, e determina a morte de Cláudio. Contudo, a fim de evitar o cumprimento da pena, Vicêncio, ainda disfarçado de padre, convence o delegado da cidade a enviar para Ângelo a cabeça de outro prisioneiro, que havia morrido. Em seguida, o duque envia uma correspondência a Ângelo, informando seu retorno, e exigindo que o encontrassem na entrada da cidade, para, em público, retomar sua posição. Ao se encontrarem, Ângelo é denunciado por Isabella, que, revelando o que ocorrera, o desmascara. O duque, então, determina que Ângelo, enfim, case-se com Mariana, e que Éscalo se case com uma alcoviteira que ele havia engravidado. Imediatamente, liberta Cláudio e pede a mão de Isabella em casamento.

A comédia retrata, em muito, o "dilema do juiz Ângelo". Em um determinado momento, está na posição de um reto e frio juiz, a aplicar a letra da lei sem exceções ou disposições morais ou políticas. Por outro lado, preenchido pela torpeza, desvirtua o sentido da lei, atuando com subjetivismo extremo, e tornando-se, de forma solipsista, um senhor da lei, absoluto proprietário de seus sentidos (STRECK:2014;338-339).

Entretanto, como poderia agir dessa forma, se, em grande parte, interpretar é dar sentido, construindo e delimitando domínios, e, com isso, torna-se um intérprete, capaz de encontrar a decisão mais adequada a casos concretos? Esse é o problema. A norma é silente, apenas representada por um texto sem significação, e que não se modifica enquanto não for interrogada, dissecada, reclamada e trazida a um presente espaço temporal, quando, finalmente, poderá expor suas potencialidades (FERNANDES-LARGO: 1993; 140).

Em ambas as condições, tanto da breve parábola de Calvino, como da comédia de Shakespere, é possível verificar como o intérprete pode, ao mesmo tempo, adotar posturas completamente distintas - em determinado momento, aplicando a lei restritivamente e, praticamente, com interpretação puramente gramatical e, em outros, de forma extensiva e servindo a valores pré-determinado no âmbito de sua compreensão.

Nesse contexto, principalmente por ser tratar do cotidiano pós-moderno brasileiro, ainda carente de proteção de direitos e garantias fundamentais, faz-se necessária uma amplificação desses parâmetros, em decorrência de ausência de qualquer movimento de estruturação de sentidos, quando da interpretação, fora das restrições promovidas pela dogmática jurídica. Mas isso não significa que não se possa alcançar um sentido verdadeiramente autêntico, ou, em outros termos, de acordo com os ditames constitucionais, ainda que provenientes da dogmática jurídica e do campo jurídico vigentes. E é o que se proporá analisar a seguir.

\section{A HERMENÊUTICA JURÍDICA CRÍTICA E O RESGATE DE UMA INTERPRETAÇÃO CONSTITUCIONAL AUTÊNTICA: INDAGAÇÕES E REFUTAÇÕES CONTRA O "ESTADO DE EXCEÇÃO HERMENÊUTICO"}

O processo hermenêutico, diferentemente daquilo que, em teoria, é realizado pela dogmática jurídica, deve ser considerado como um devir, uma vez que interpretar é dar sentido, ou seja, construir sítios de significância, e tornando possíveis gestor de interpretação (STRECK:2014; 338). Nesse contexto, o Direito, consequentemente, deve ser compreendido não como uma sucessão de textos com sentidos latentes, aguardando sentido, ou ainda préconstruídos, a partir da pré-compreensão dos juristas e demais intérpretes daquilo que a 
dogmática jurídica, respaldada por um campo jurídico - ainda de cunho liberal-individualista tenta transmitir.

Muito pelo contrário, faz-se necessária uma hermenêutica jurídica crítica para efetuar o resgate ao sentido, e, ao mesmo tempo, que se reforce a interpretação constitucional autêntica, em desconstituição daquilo que se pode denominar como um "estado de exceção hermenêutico", ou seja, uma interpretação jurídica que se transformou em um conjunto de posturas e teses utilizadas sem critério, sem preocupações teórico-sistemáticas. Deve-se evitar, em outros termos, um ativismo judicial com caráter autoritário nos seus sentidos, e que age, muitas vezes, em termos de contingência, a partir de cada caso concreto. Por outro lado, não se pode olvidar de estabelecer uma relação de relevância e consideração pelo texto constitucional vigente, que atuará como referencial hermenêutico.

O que se verificou, quando da análise dos julgados acerca da imunidade tributária de livros e assemelhados, com sua devida extensão, é que o campo jurídico vivenciado em território brasileiro propicia a aplicação, e eventual consideração de elementos eminentemente dogmáticos, sem questionamentos necessários e, quando em sentido contrário, são utilizados para suprir uma lacuna de proteção e garantismo processuais, gerado por um texto constitucional amplo em tratamento de direitos e garantias fundamentais, mas com um modo de produção jurídico de sua teoria, e ainda com características liberais.

Em suma, resta evidenciado que existe, em plena pós-modernidade, e com um texto constitucional de cunho democrático, uma espécie de "pacote significante", e que contém, em seu cerne, um discurso cuja condição de verdade (e validade) é exatamente uma aparência de que os sentidos estão submersos, ou ainda ocultos por uma realidade sociojurídica. Nesse ínterim, a tarefa do hermeneuta resume-se a trazer à tona uma verdade revelada (STRECK:2014; 339). Porém, sem perceber o contexto em que está inserido, ou mesmo o seu papel nesse campo jurídico, não permite o alcance do autêntico sentido a que deveria destinar-se aquela disposição.

O Estado Democrático de Direito tem, por característica essencial, a necessidade de superação do modelo do Estado Liberal de Direito, com viés individualista e direcionado ao cumprimento estrito da legalidade, mas, também, o do Estado Social de Direito (também denominado Welfare State), e que têm moldes amplamente capitalistas. Essa medida impõe à ordem jurídica e à atividade estatal um conteúdo praticamente utópico de transformação da realidade (MORAIS; 1996: 67-68). Consistindo em representação da vontade constitucional de realização do Estado Social (que restou muito distante de ocorrer em solo brasileiro), converte-se em uma adição normativa em relação ao modelo de Estado provedor-intervencionista, e, ainda assim, diferente do modelo individualista do Estado Liberal de Direito (STRECK; 2014: 45-47).

Portanto, a elaboração de um discurso crítico torna-se condição necessária para ultrapassar os limites impostos pelo campo jurídico e, essencialmente, pela dogmática jurídica vigente, que, ainda indiretamente, resta por não inovar no campo jurídico, ou permitir uma saída ao "estado de exceção hermenêutico", com dupla personalidade, em que se encontra. Uma vez que o texto, por si só, não irá trazer o próprio sentido (ou o sentido esperado ou exigido pelo campo jurídico ou contexto social em que se insere a norma), tornam-se inexistentes meros julgamentos com cumprimento da lei em seu sentido meramente gramatical, ou julgados que estejam em contrariedade a esse parâmetro legal (MÜLLER: 1993; 169-170).

Em decorrência, o magistrado profere um julgamento considerado em contrariedade à lei, mas, na realidade, está a proferir um julgado contra o cerne da doutrina e jurisprudência estabeleceram como juridicamente prevalecente do sentido daquele texto normativo. Trata-se, em suma, de um processo de produção e construção de sentido, que ocorre por outro processo, mediante uma simbolização (de teorias, da palavra, entre outras) (STRECK:2014; 341).

Por outro lado, faz-se necessária uma hermenêutica que rompa com os paradigmas filosóficos e realísticos, ainda presentes no ordenamento jurídico pátrio e no modo de produção do Direito, e que permita ao conteúdo do texto jurídico ser aplicado na sua literalidade (o que, 
muitas vezes, já é um avanço), mas, também, nos silêncios produzidos pelo texto. Mas, não se pode deixar de lado o caráter de autenticidade da norma, respaldada por um Estado Democrático de Direito, e mediante um texto constitucional vigente. Trata-se, em consequência, de uma aplicação e interpretação da norma com limites semânticos, resguardando a legalidade - que, muitas vezes, deixa de ser uma mera legalidade, como no caso do julgado em apreço, e que consiste no título deste trabalho - mas, ainda, uma legalidade constitucional.

Cada sociedade, por sua vez, tem um campo jurídico próprio sob a qual se molda, e, consequentemente, este mesmo campo jurídico, que pode ser encarado como um senso comum teórico de muitos juristas, é que sustentará o modo de produção do intérprete. Mas esse senso comum, no Brasil, é que faz permanecer um modo liberal-individualista-normativista de produção do jurídico, e que apenas solidifica as fissuras decorrentes do abismo que existe entre o discurso jurídico prometido e a estrutura social carente de direitos e garantias fundamentais efetivamente concretizadas.

Um texto jurídico possui uma série de sentidos diferenciados, mas, para que se quebre o "estado de exceção hermenêutico", repleto de discricionariedades (ou falsas discricionariedades, uma vez que somente será discricionário nos limites da dogmática jurídica em que se inserem os intérpretes e aplicadores da norma), e busque-se um sentido autêntico, a partir do texto constitucional vigente.

\section{CONCLUSÃO}

Pode-se concluir diante de todo o exposto que, mesmo diante de um cenário pósmoderno de construção estatal, com um Estado Democrático de Direito estabelecido - mas não aplicado, em concreto, na maioria dos setores sociais - o ordenamento jurídico brasileiro ainda apresenta crises paradigmáticas.

Por um lado, o campo jurídico apresentou demandas e expectativas que não têm mais condições de serem atendidas por um modelo liberal-individualista do Direito. Ao mesmo tempo, o intérprete está diante de um modo de produção que é, simultaneamente, instituinte e instituidor de práticas jurídico-dogmáticas. E essa medida impede que o sentido da norma seja alcançado em sua completude, ou, ainda, que se formem excessos.

Nesse contexto, urge, da análise do julgado acerca da concessão de imunidade tributária ao poder-dever de tributar, do artigo 150, inciso VI, alínea "d", ao colectible card game, que o STF está inserido nesse campo jurídico de cunho liberal-individualista, e que esse modo de produção não pode suprir as necessidades e expectativas geradas pelo ordenamento jurídico constitucional.

Estabeleceu-se, muitas vezes, uma dupla personalidade, atuando praticamente de contingência, a partir de cada caso concreto, e que apenas dificulta o alcance do sentido autêntico da norma. Entretanto, o que se verifica é um estabelecimento de um "estado de exceção hermenêutico", que promove uma série de efeitos no ordenamento jurídico pátrio, e, consequentemente, gera insegurança jurídica.

Mas, a partir de uma hermenêutica crítica, faz-se necessário que se resgate o autêntico sentido da norma, e que se permita ao intérprete e aplicador do Direito a aferição do sentido a ser aplicado, em decorrência da dogmática jurídica respaldada pelo campo em que se insere. Não pela limitação da norma, nem pela sua extensão sem fundamento, mas com respeito à ordem constitucional vigente. 


\section{REFERÊNCIAS BIBLIOGRÁFICAS}

ANDRADE, José Carlos Vieira de. Os Direitos Fundamentais na Constituição Portuguesa de 1976. Coimbra: Almedina, 1998.

ATALIBA. Geraldo. Hipótese de Incidência Tributária. 4. ed. São Paulo: Revista dos Tribunais, 1991.

BALEEIRO, Aliomar. Direito Tributário Brasileiro. 11. ed. Rio de Janeiro: Forense, 2007.

BECKER, Alfredo Augusto. Teoria Geral do Direito Tributário. 5. ed. São Paulo: Noeses, 2010.

BLUMENSTEIN, Ernst. Sistema di Diritto delle Imposte. Milão: A. Giuffre, 1954.

BUJANDA, Fernando Sainz de. Hacienda y Derecho: estudios de derecho financiero. Madrid: Instituto de Estudios Politicos, 1966, t. IV.

CALVINO, Italo. Se una notte d'inverno un viaggiatore. Milão: Mondadori, 1980.

COSTA, Adriano Soares da. Teoria da Incidência da Norma Jurídica: crítica ao realismo lingüístico de Paulo de Barros Carvalho. Belo Horizonte: Del Rey, 2002.

FERNANDES-LARGO, Antonio Osuna. La hermenéutica jurídica de Hans-Georg Gadamer. Valladolid: Universidad de Valladolid, 1993.

FOROUNGE, Carlos María Giuliani. Conceitos de Direito Tributário. São Paulo: Edições Lael, 1973.

JARACH, Dino. O Fato Imponível: teoria geral do direito tributário substantivo. São Paulo: Revista dos Tribunais, 1989.

GIANNINI, Acchile Donato. Instituciones de Derecho Tributario. Madrid: Editorial de Derecho Financiero, 1957.

MARQUES NETO, Floriano Peixoto de Azevedo. Regulação estatal e interesses públicos. São Paulo: Malheiros Editores, 2002.

MIRANDA, Francisco Cavalcanti Pontes de. Tratado de Direito Privado. Rio de Janeiro: Borsoi, 1954, t. I.

MÜLLER, Friedrich. Direito, linguagem, violência: elementos de uma teoria constitucional. Porto Alegre: Fabris Editor, 1995, vol. I.

NOGUEIRA, Ruy Barbosa. Curso de Direito Tributário. 10. ed. São Paulo: Saraiva, 1990.

Jospe Bushatsky Editor, 1974.

Da Interpretação e da Aplicação das Leis Tributárias. 2. ed. São Paulo:

SOUSA, Rubens Gomes de. Compêndio de Legislação Tributária. São Paulo: Resenha Tributária, 1975.

STRECK, Lenio Luiz. Hermenêutica Jurídica e(m) Crise: uma exploração hermenêutica da construção do Direito. 11. ed. Porto Alegre: Livraria do Advogado, 2014. 
VASCONCELOS, Arnaldo. Teoria da Norma Jurídica. 6. ed. São Paulo: Malheiros Editores, 2006.

WARAT, Luiz Alberto. Introdução geral ao Direito II. Porto Alegre: Fabris Editor, 1995. 